\title{
A Professional Mode of the Transformation of Sci-tech Achievements in Scientific Research Institutions of Tianjin City
}

\author{
Fu Qiang; Zhao Lihua; Dong Shugong \\ Tianjin University of Technology and Education, Tianjin China, 300222
}

\begin{abstract}
There are too many scientific research institutions in Tianjin, and the scientific research activities are very active. The transformation of Sci-tech achievements is badly in need of a set of suitable and standardized mode, and how to establish this kind of mode is an important problem faced by researchers of Tianjin Sci-tech development. Based on analyzing the situation in Tianjin research activities, the paper proposes a way to solving this problem--the professional mode of the transformation of Sci-tech achievements, illustrates the connotation of the professional mode, and describes the implement environment and the specific operation progress. According to the characteristics of factors in Tianjin, such as society, government, market, industrial technology and so on, the paper designs the professional mode of the transformation of Sci-tech achievements, which is suitable for the characteristics of Tianjin, and which plays an important role in promoting the development of the productive force in science and technology of Tianjin.
\end{abstract}

Keywords: Sci-tech Achievements; Professional Mode; Scientific Research Institutions

As the strategy is put forward that Tianjin is going to be constructed into an international port city and the northern economic center and the Binhai new area is being developed and constructed, the economy of Tianjin has developed rapidly. In the fast-growing GDP, which is mainly contributed by the productive force in science and technology, the relationship between the Sci-tech development and the economic development is becoming closer. The transformation of Sci-tech achievements is badly in need of a set of suitable and standardized mode, and how to establish this kind of mode is an important problem faced by researchers of Tianjin Sci-tech development.

\section{Situation of Scientific Research Activities in Tianjin City}

In Tianjin, institutes engaged in relevant activities of science and technology includes scientific research departments in colleges and universities, all kinds of scientific research institutes, $R \& D$ departments in enterprises and so on. Statistically, Tianjin has 55 kinds of colleges and universities at present including 16 comprehensive universities and about 28,919 full-time teachers. There are 140 institutes of independent scientific research and technological development, and workers engaged in scientific research activities are about 13,211. In 2011, there are 36,258 patent applications accepted, including 13,982 applications for authorization counted, about $38.6 \%$ of the total number. The situation of patent applications and authorizations is shown in Figure 1 from 2001 to 2011. In 2011, the expense of science and R\&D is 29.776 billion yuan, and there are 2,020 registrations of municipal Sci-tech achievements, including 59 international leading Scitech achievements.

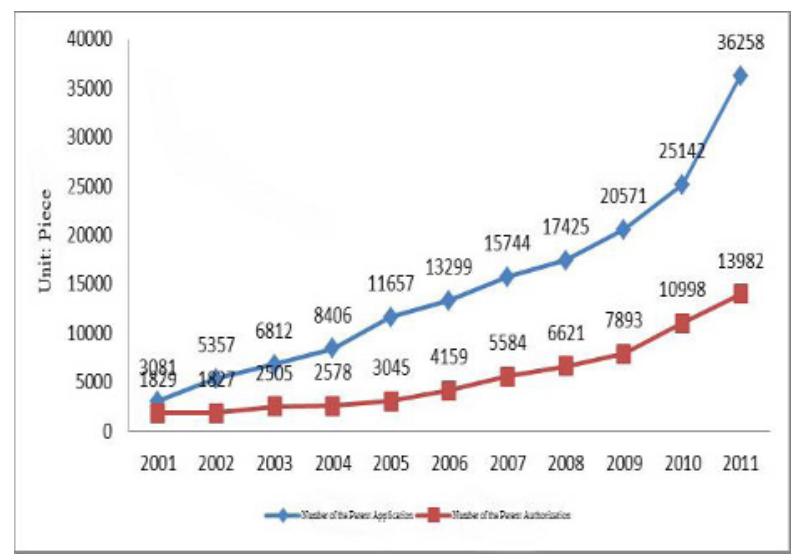

Figure1. The Situation of Patent Applications and Authorizations from 2001 to 2011

In order to support the sustainable development of Sci-tech activities, the funds, about $3.3 \%$ of the local finance in Tianjin, is extracted and used to support Scitech activities every year ${ }^{[1]}$. However, it is shown in figure 1 that the number of the patent application and authorization has been rising year by year, and that the difference between them has been becoming bigger. In many Sci-tech achievements, the real practical application is relatively less presenting the phenomena 
of low conversion rate and achievements on the shelf. Thereinafter, it is imminent to solve problems of the transformation of Sci-tech achievements and further liberate the productive force of science and technology.

\section{Research Status of the Transformation Mode of Sci-tech Achievements}

In 1912, Joseph Alois Schumpeter, an economist, firstly put forward the concept of "innovation theory" in his work, which started the research on the theory of the technological innovation ${ }^{[2]}$. Professor Mansfield in American Carnegie Institute of Technology made deep research on the "promotion" problem of the new technology in 1950. Thereafter P. Stonman, C. Frecman, L. Scholtz and other people made a further research and discussion on the "promotion" problem of the technology on the basis of the Mansfield's research. The concept of "the transformation of Sci-tech achievements" is rarely used in the research of foreign scholars, always replaced with "the technological innovation and the realization of the productive force", and mostly ex-pressed in "technology transfer".

Based on the theory of the technological innovation and technological diffusion, domestic scholars make an empirical analysis on the transformation of Sci-tech achievements in China ${ }^{[2]}$. Zhangping Lu and Xiaojing Wang researched the transformation of Sci-tech achievements in China from the point of policy using the content analysis, and evaluated the usage and existent problems of the policy instrument ${ }^{[3]}$. Based on the triple helix model theory of the government-industryuniversity, Lei Zhao and Shulei Wang made a deep analysis on many complex concepts and their relations in the process of the organization operation on the transformation of Sci-tech achievements to provide a referential thinking for the operation mechanism of the transformation of Sci-tech achievements ${ }^{[4]}$. Xiaofeng Li, Shuangshuang Wang, Lu Jin and other people established the concept and system model of the collaborative innovation carried out by Sci-tech service agents from 3 points, strengthening the communication and cooperation among Sci-tech service agents, functional localization and service target, and put forward the collaborative way of different institutes taking Tianjin city as the example ${ }^{[5]}$. Zhenya Hu divided the incentive mechanism of the transformation of Scitech achievements into 4 types, which are the input incentive mechanism, the interest incentive mechanism, the responsibility incentive mechanism and the concept incentive mechanism ${ }^{[7]}$. Kongyue Li gave suggestions on speeding up the transformation of Sci-tech achievements in China in aspects of the scientific research guide, the source of funds, the scientific research subject, the scientific research management, governmental function and others by comparing the characteristics of the transformation mode of Sci-tech achievements among America, Germany, British, Japan and other countries ${ }^{[8]}$. Chuanhui Huang, Yanning Zheng and Chunyu Wu researched "Wisconsin Idea" in the transformation of Sci-tech achievements in America, analyzed the operation mechanism of the transformation of Sci-tech achievements in America and provided a beneficial reference for the transformation of Sci-tech achieve-ments in China in the aspect of policy formulation and implementation ${ }^{[9]}$.

\section{Connotation and Analysis on the Profess- ionalization of the Transformation of Sci- tech Achievements}

The operation mode of the professionalization refers to fulfilling the evaluation, the cultivation, the demonstration and the promotion of Sci-tech achievements, enhancing the value of Sci-tech achievements in maximum, completing the transformation of practical productive force at full speed, and successfully bringing it to the market.

The so-called professionalization, that is the standardization, the normalization and systematism of a kind of working state, refers to requiring workers to professionally complete job responsibilities assigned by society or organizations at their best and correctly playing his own role in the work. The concept of the professionalization synonymous with the specialization and the commercialization refers to the core characteristics of OTT operation. There are a few conditions to realize the specialization: professional high-end talents carry out the work of technology transfer; the mechanism is flexible and the finance is independent; operated according to the marketization; enhancing the value of the patent in maximum; and successfully bringing it to the market ${ }^{[11]}$.

There are too many scientific research institutions in Tianjin at present, and the corresponding Sci-tech service institutions have also possessed a certain scale. And there are a number of Sci-tech service institutions such as Sci-tech consultation, Sci-tech incubator, Scitech information service, the productive force of the industry and so on, which form a certain feature. While in aspects of the scale, the function, normalization and others, many Sci-tech service agents still exist a series of weakness, such as the small scale, the less total number, the imperfect function, irregular operating process, the network organization without forming the resource sharing in the whole city and so on. In order to solve the problem, a set of the transformation mode of Sci-tech achievements, which is standardized, professional and perfect, should be set up. Through the mode, the resources of the Sci-tech service in the whole city are unified and standardized to realize the programming, normalization and professionalization of the transformation of Sci-tech achievements.

\section{Establish the Professional Operation Mode of the Transformation of Sci-tech Achievements}

\subsection{Principle of Establishment}

1) To meet the needs of the economic structure, the economic development and the industrial distribution in Tianjin City;

2) To be dominated by the market demand and to get the strong support and the guide from government departments as the supplements; 
3) To establish the thoughts of the Sci-tech innovation and the leapfrog development;

4) To consider the enterprise as the core and supporting policies as the supplements.

\subsection{Goal of Establishment}

1) To be able to make the process of the transformation of Sci-tech achievements standardization, and normalization and professionalizetion in Tianjin City;

2) To increase the transformation rate of Sci-tech achievements, to speed up the process of the industrialization of achievements and to improve the quality of the economic operation;

3) To promote the development of the pillar industry, to improve the technological level and to speed up the application of achievements;

4) To connect enterprises and scientific research institutions, to simplify the procedure, and to speed up the industrialization of the high and new technology and the product.

5) To help to motivate Sci-tech workers to conduct the scientific research with the driving force.

\subsection{Location Analysis on the Professional Service of the Transformation of Sci-tech Achievements in Tianjin City}

The professional service of the transformation of Scitech achievements is between enterprises and scientific research institutions. On the one hand, the transformation of Sci-tech achievements is promoted and transferred into the productive force of the science and the technology to provide service for the needs of society. On the other hand, the scientific research workers are motivated to conduct the innovation through the achievement transformation and the profit distribution. It is shown as figure 2.

1) The Social Environment. The Sci-tech service pattern has basically developed in Tianjin, in which public institutions and private institutions coexist and public institutions and non-government institutions complement each other and mutually develop ${ }^{[5]}$. There are more than 100 intermediary service institutions mainly operating technological trading, and there are all kinds of service institutions such as the Sci-tech assessment, the information research, the enterprise incubation, the promotion center of the productive center

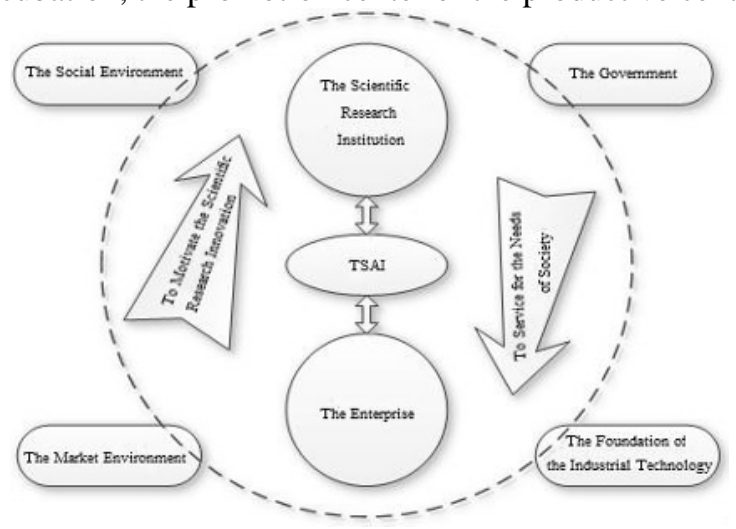

Figure 2. The Professional Location of the Transformation Institution of Sci-tech Achievements and so on at present in Tianjin, which initially shape a group of backbone industries in the Sci-tech service industry. While there are some disadvantages in the current system such as the dispersed structure, the simple institution location, the narrow coverage and so on, and there are some aspects which are not perfect, including the system construction, the industrial development, the construction of the service institution, the layout of the service industry and other aspects.

2) The Function of Government. As an important part of the operation mechanism of the transformation of Scitech achievements, government is not only the rule maker, but also the direct participant in the activities of the transformation of Sci-tech achievements in the activities of the transformation of Sci-tech achievements ${ }^{[4]}$. Government plays a crucial role in perfecting laws and regulation system, investing continued funds, supervising and managing the service process and other aspects. At present, Tianjin has issued a series of policies and regulations related to the transformation of Sci-tech achievements such as "Regulations to Promote the technological Trading of Tianjin City", "Regulations to Promote the Transformation of Sci-tech Achievements of Tianjin City (2001 Revision)", "Regulations of the Sci-tech Popularization of Tianjin City", "Management Regulations of New Technological Industrial Park of Tianjin" and others, which develop a rather perfect laws and regulations system.

3) The Influence of the Market Environment. The market mechanism is the basic driving force for the service development of the transformation of Sci-tech achievements. Constructing the reasonable transformation mode of Sci-tech achievements shall be guided by the market and realized according to the market mechanism.

4) The Basis of the Industrial Technology. At present, there are 46 institutes located in Tianjin altogether, which is appointed by the central committee, including 38 scientific research institutes and 8 engineering design institutes. There are 7 military industrial institutes and 39 non-government institutes. There are 113 municipal scientific research institutes, including 72 scientific research institutes of technological development and 41 scientific research institutes of social welfare. In 2012 , there are 767 companies to take part in research of Scitech project, including 21 colleges and universities, 663 enterprises, 69 public institutions like scientific research institutes, and 14 institutes (data source: the 2012 Executive Report of the Sci-tech Project of Tianjin). Regardless of the quantity and the scale or the quality, Tianjin has possessed a stronger industrial technological basis.

\subsection{The Professional Operation Process of the Transformation of Sci-tech Achievements}

4.4.1. To establish the professional transformation of Sci-tech achievements institution (Transformation of Sci-tech Achievements Institutions, TSAI), and to provide an open, professional and normalized service of the transformation of Sci-tech achievements for society. The professional transformation of Sci-tech achievements institution is an independent entity, which usually 
attaches to universities or scientific research institutes and provides an open, professional and normalized service of the transformation of Sci-tech achievements for society.

The professional transformation of Sci-tech achievements institution is divided into 6 parts, including achievement evaluation department, licensing commissioners, the patent agent, marketing department, commercial operation department and the administrator of proceeds distribution (shown in Figure 3).

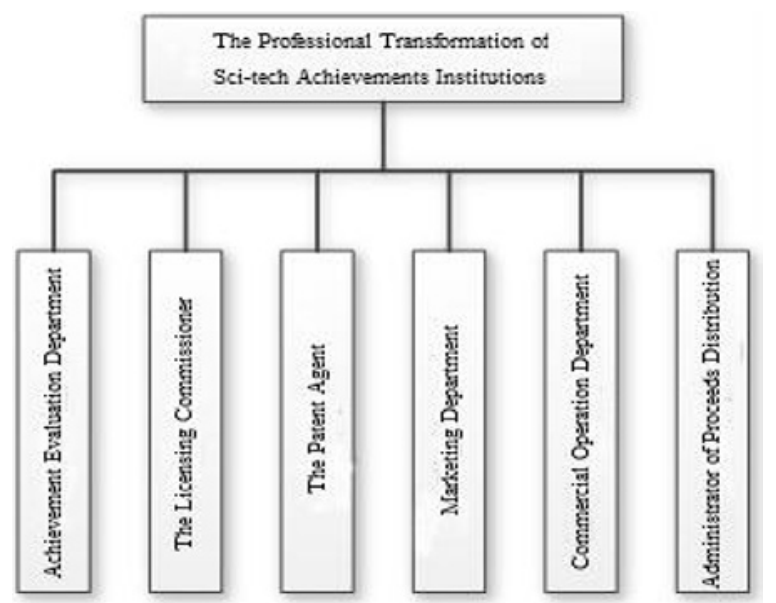

Figure 3. The Professional Transformation of Sci-tech Achievements Institutions

4.4.2. The Professional Operation Progress of the Transformation of Sci-tech Achievements. The professional transformation of Sci-tech achievements institution is divided into several parts, including achievement evaluation department, licensing commissioners, the patent agent, marketing department, commercial operation department and the administrator of proceeds distribution, which provides a series of full and professional service for the transformation of Sci-tech achievements from the achievement announcement to the product application. (The process is shown in Figure 4 ).

\section{1) Sci-tech Achievement Announcement}

After the Sci-tech workers fulfill achievements, they shall announce to TSAI. The staff of TSAI shall ask them to fill out an announcement report, then assign the achievement to licensing commissioners of the corresponding technological field to be in the stage of the achievement confirmation and the evaluation.

\section{2) Achievement}

After receiving the achievement announcement, licensing commissioners shall make the initial screening and evaluation to confirm that the achievement possesses the value of application. In this process, licensing commissioners shall communicate with the inventor to further learn the relevant index and technology system through meetings, written reports and so on. Then, licensing commissioners shall require the technological workers to submit the self-assessment report of the achievement, and employ specialists, scientific research workers and technicians of enterprises in the research field to take part in the discussion and evaluation about the technological content of the achievement. The main evaluation contents include the legal evaluation, which is if the achievement accords with the relevant laws and regulations and if it violates the social ethics and moral and so on; the practical evaluation, which is if it possesses the practical value; the maturity evaluation, which is that if the achievement is in the initial stage or less mature, it shall be returned to the technician and transformed after it is perfect; the market potential evaluation, which is evaluating the market potential after it is transformed into the product; the cost evaluation, which initially evaluates its licensing cost.

\section{3) Protection Measure of the Achievement}

After fulfilling the procedure of the achievement evaluation and confirming that it possesses the promotional value, licensing commissioners shall draw a set of instructional protection strategies of the achievement, including the patent application strategy and the authorization and protection strategy of the intellectual property. For the achievement which does not need the patent application, it may be transferred by direct permission to transfer. While for the achievement which needs the patent application, a patent application strategy is needed to be drawn to successfully pass the application and reduce the risk of the achievement loss. The patent application strategy includes the time, the content, the place and others of the patent application.

\section{4) Marketing}

After fulfilling the protection measure of the achievement, licensing commissioners shall submit the achievement to the marketing department. There is a professional team to conduct the marketing of the Scitech achievement in the marketing department. Firstly, they seek some potential cooperation enterprises in the market, then present the partial details of the achieve ment and the application prospect transferred. Meanwhile, the marketing team shall feedback the improvement and suggestion of the achievement to licensing commissioners, who feedback it to the technician to improve and optimal design.

\section{5) Commercialization}

After the target enterprise is chosen through the marketing, licensing commissioners meet and negotiate with the enterprise to confirm the authorization plan of the achievement. Licensing commissioners shall choose the appropriate licensing pattern to authorize the enterprise to transfer the achievement. After confirming the agreement, TSAI shall sign the cooperation agreement with the enterprise, and notice the content of the agreement to the Sci-tech workers.

6) Industrial Application and Distribution of Proceeds

After signing the license agreement with the target enterprise, TSAI shall be responsible for receiving the agreed funds paid by the enterprise and converting it into proceeds agreed in the agreement. After signing the licensing agreement and establishing the authorization cooperation relation with the enterprise, licensing commissioners shall also keep a long-term contact and 


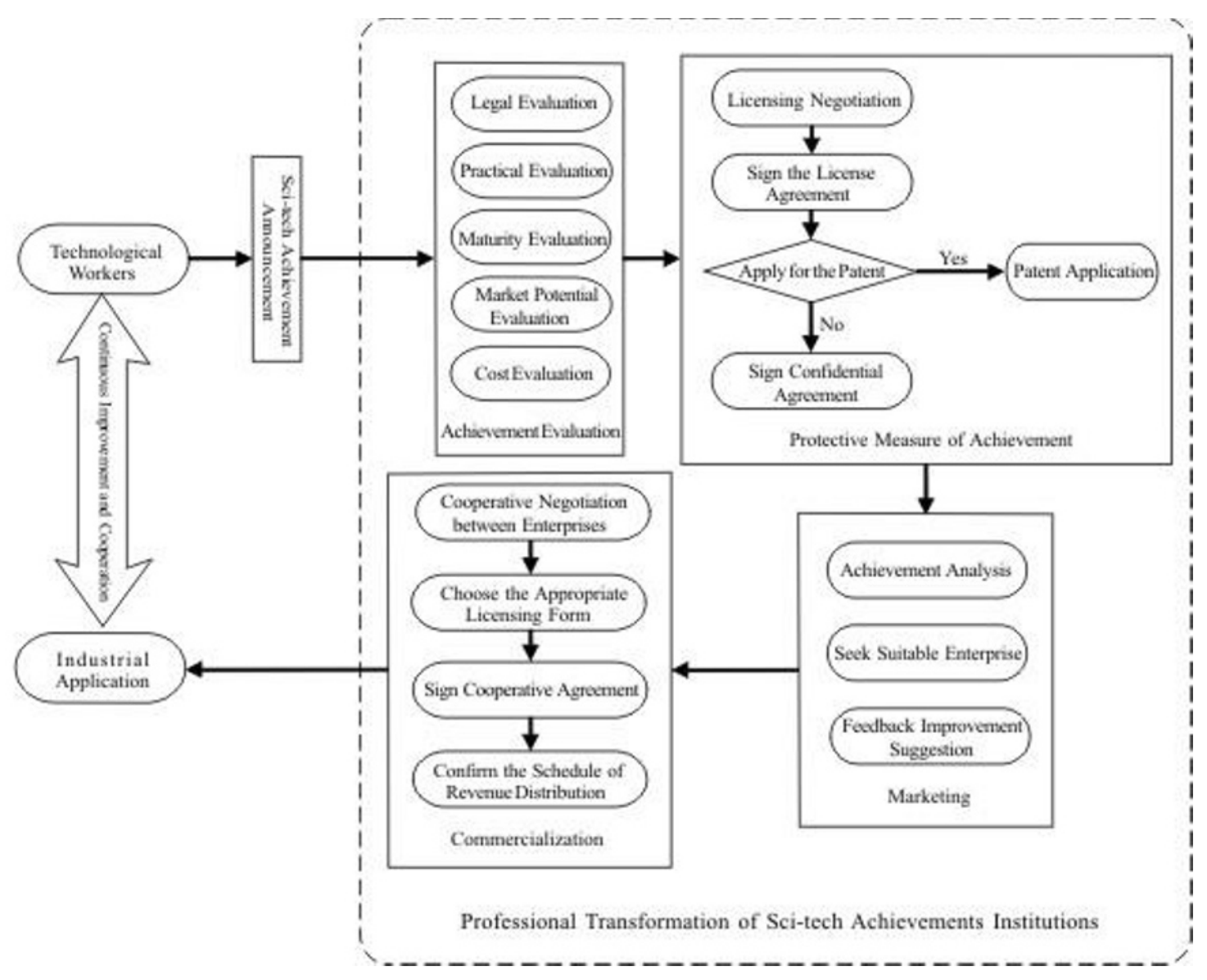

Figure 4. The Professional Mode Operation Process of the Transformation of Sci-tech Achievements

communication with the enterprise and the investor, learn the continued research and market promotion situations, then feedback the above situations to technicians to help to further improve and perfect the achievement. The Sci-tech workers may be motivated by the new scientific research work to evoke the Sci-tech productive force through proceeds distribution.

\section{Conclusion}

The transformation of Sci-tech achievements is a complex process which is needed to invest and operate together in many aspects, in which the smooth operation is in need of an operation mode, reliable and professional. There are too many scientific research institutions in Tianjin where there are a better environment for the scientific research development. From the points of government, society, scientific research institutions etc, the transformation mode of Scitech achievements is constructed to be complete, nonstop and professional and the current conflict situation between many Sci-tech achievements and low transformation rate is improved. Both of these play an important role in promoting the development of the Scitech productive force.

\section{References}

[1] Wang Xiaoli, Zhang Hongpu, "Current Situation Research on the Transformation of Sci-tech Achievements of Tianjin City,"
[J]. Technological Development of Enterprise, 2012 (5), pp. 16-17+21.

[2] Wang Yumei, Wang Xiantao, "Knowledge Sharing Research Review and Outlook of the Transformation of Sci-tech Achievements," $[\mathrm{J}]$. the Journal of Qingdao University of Science \&Technology (Social Science), 2009 (2), pp. 89-93.

[3] Lu Zhangyu, Wang Xiaojing, "Research on the Policy of the Transformation of Sci-tech Achievements on the Basis of Content Analysis," [Z]. 2013.

[4] Zhao Lei, Wang Shulei, "Research on the Operation Mechanism of the Transformation of Sci-tech Achievements on the Basis of the Triple Helix Theory," [J].China Fisheries,2013(3), pp.31-33.

[5] Li Xiaofeng, Wang Shuangshuang, Lujin etc. "Collaborative Innovation Model and Pattern Research among Sci-tech Intermediary Service Institutions on the Basic of the Case of Tianjin," [J]. Scientific Management Research, 2012 (6), pp. 47-50.

[6] Gao Lina,Gao Shujie, "Function Discussion about the Transformation of Sci-tech Achievements of Sci-tech Inter-mediary Institution," [J].Reform and Strategy, 2012 (5), pp.184-186.

[7] Hu Zhenya, "On the Implementing Body, the Transformation Mode and the Incentive Mechanism of the Transformation of Sci-tech Achievements," [J].Seeker, 2012 (12), pp. 178-180.

[8] Li Kongyue, "Mode Comparisation and its Revelation of the Transformation of Sci-tech Achievements," [J]. Scientific Management Research, 2006 (1), pp. 92-95.

[9] Huang Chuanhui, Zheng Yanning, Wu Chunyu, "Research on the Transformation Mechanism of American Sci-tech Achievements," [J]. Hubei Social Sciences, 2011(10), pp. 83-86

[10] He Defang, "Discrimination and Thought about Certain Basic Concepts of Sci-tech Achievements and Achievements Transformation," [J]. China Soft Science, 2011 (11), pp. 6-12.

[11] Di Xiaoyan, "International Professional Mode in the Transformation of Sci-tech Achievements," Scientific Management Research, 2011 (3), pp. 50-52 